NIVO TOPLOTNOG STRESA KOD VOZAČA POLJOPRIVREDNIH TRAKTORA PRILIKOM SPREMANJA SILAŽE

\title{
HEAT STRESS LEVEL IN THE DRIVERS OF AGRICULTURAL TRACTORS DURING AN ENSILING
}

\author{
Prokeš $B^{1}$, Mačvanin $\operatorname{Nada}^{1}$, Simikić $M^{2}$, Savin $L^{2}$, Španović $M^{1}$ \\ ${ }^{1}$ Zavod za zdravstvenu zaštitu radnika, Futoška 121, Novi Sad \\ ${ }^{2}$ Univerzitet u Novom Sadu, Poljoprivredni fakultet, Trg Dositeja Obradovića 8, Novi Sad, Srbija \\ e-pošta: prokes@eunet.rs
}

\section{SAŽETAK}

Kvalitet mehanizacije svoj uticaj na zdravlje vozača-rukovaoca ostvaruje direktno putem fizičkih i hemijskih štetnosti poreklom iz radne sredine (mikroklimatski parametri, buka, vibracije, izduvni gasovi, prašina i sl), izazivajući profesionalna oboljenja, i indirektno, putem višestrukih i raznorodnih uzroka, izazivajući pojavu bolesti vezanih uz rad.

Indeks vlažnog globus termometra (WBGT index) je najčešće korišćeni indeks za procenu toplotnog stresa u različitim oblastima ljudske delatnosti (industriji, poljoprivredi, vojsci, sportu) (ISO 7243:2003).

Merenje toplotnog stresa (WBGT indeksa) vozača poljoprivrednih traktora i mobilnih sistema obavljeno je prilikom uobičajenog režima rada posmatranih mašina u skladu sa tehnološkim postupkom spremanja silaže.

Vremenski uslovi su bili: sunčano, potpuno bez oblaka; temperatura spoljnog vazduha $21,2^{\circ} \mathrm{C}$; relativna vlažnost vazduha $48 \%$; brzina vetra $0,9-2,3 \mathrm{~m} / \mathrm{s}$; WBGT index $20,6^{\circ} \mathrm{C}$.

U skladu sa odgovarajućim uslovima referentna vrednost WBGT indeksa postavljena je na $28^{\circ} \mathrm{C}$.

Merenje je obavljeno u kabinama traktora John Deere 8320, John Deere 6820 i Belarus MTZ 820, kao i utovarivača ULT 100 i guseničara BNT 14 oktobar.

Vrednosti WBGT indeksa kretali su se u rasponu od $22,7{ }^{\circ} \mathrm{C}$ do $28,6{ }^{\circ} \mathrm{C}$.

Obzirom na vremenske uslove spolja koji su vladali tokom merenja WBGT indeksa i utvrđene vrednosti indeksa može, se zaključiti da je kod vozača posmatranih poljoprivrednih traktora i mobilnih sistema toplotni stres bio na srazmerno visokom nivou, bez obzira na korišćenje raspoloživih ventilacionih uređaja u kabinama (osim klima uređaja ako je i bio na raspolaganju).

Ključne reči: Poljoprivredni traktori, toplotni stress, WBGT indeks, profesionalni rizici. 


\section{UVOD}

U savremenim traktorima i mobilnim sistemima koja se koristi u poljoprivredi kvalitet radnih uslova vozača je na zavidnom nivou sa stanovišta zdravlja i bezbednosti. Međutim, to nije slučaj kada su u pitanju stari traktori i mobilni sistemi.

Prema popisu koji je obavljen krajem 2012. godine Republika Srbija raspolaže sa 408.734 traktora svih kategorija (Prostran, 2013).

Prema Nikoliću i saradnicima starosna struktura je veoma nepovoljna i prelazi 10 godina na društvenom - državnom i 15 godina na privatnom sektoru, odnosno preko $35 \%$ traktora starije je od 15 godina (Nikolić et al, 2013)..

Prema Laziću i saradnicima, te Malinoviću i Mehandžiću poljoprivreda Vojvodine je do 1990. godine bila dobro opremeljena mašinama, prihvatljivog kvaliteta i učinka. Od te godine, pa sve do 2000. godine mašinski park gotovo da se nije obnavljao (Lazić i dr. 2002). Starost traktora je povećana na preko 15 godina, a prosečna starost priključnih mašina je preko 20 godina, te berača $\mathrm{i}$ samohodnih kombajna od 15 do 17 godina (Malinović i Mehandžić, 2001). Obnavljanje mehanizacije pokušano je poslednjih godina, na razne načine (krediti, lizing, zamena "staro za novo" i sl), sa manjim ili većim, ali uglavnom nezadovoljavajućim efektom.

U domaćoj poljoprivrednoj proizvodnji, mada zastarele, poljoprivredne mašine uspevaju da ostvare produktivnost, i kvalitet i manji nivo inputa po jedinici proizvoda $\mathrm{i} / \mathrm{ili}$ površine. Pri tome važna odlika postaje njihov uticaj na životnu sredinu i na zdravlje rukovaoca (Martinov i dr, 2005).

Takav kvalitet mehanizacije svoj uticaj na zdravlje vozača-rukovaoca ostvaruje direktno putem fizičkih i hemijskih štetnosti poreklom iz radne sredine (mikroklimatski parametri, buka, vibracije, izduvni gasovi, prašina i sl), izazivajući profesionalna oboljenja, i indirektno, putem višestrukih i raznorodnih uzroka, izazivajući pojavu bolesti vezanih uz rad.

Činjenice o starosti mehanizacije važne su i sa aspekta opremljenosti mašina uređajima za kontrolu parametara mikroklime u njihovim kabinama, u smislu da stariji traktori i mobilni sistemi uglavnom ne poseduju klima uređaje, a retko raspolažu i odgovarajućim sistemima prinudne ventilacije.

Noviji traktori i mobilni sistemi, pogotovo oni veće snage, uglavnom raspolažu odgovarajućim klima uređajima i ventilatorima koji utiču na stanje toplotnog konfora u kabini (Časnji F i saradnici 2002; 2003; 2004).

Ružić sa saradnicima (2005) istakli su da su osnovne konstruktivne karakteristike traktorske kabine od značaja za mikroklimu u njoj jesu veliki procenat staklenih površina, relativno mala zapremina prostora i blizina izvora toplote (motor i transmisija), što uz rad bez česte promene pravca kretanja u okruženju gde nema prirodnih zaklona od sunca znači izloženost vozača izuzetno velikim toplotnim opterećenjima.

Dalje, oni navode da traktori sa kabinom u cilju kontrolisanja mikroklimatskih parametara uglavnom koriste prirodnu i veštačku, prinudnu, ventilaciju kabine.

Po njima, prirodna ventilacija se ostvaruje otvaranjem vrata, bočnih prozora, kao i zadnjeg prozora, međutim zbog uslova eksploatacije traktori se uglavnom kreću malim brzinama, što istovremeno znači i male brzine vazduha kod prirodne ventilacije. 
Takođe prema Ružiću i saradnicima (2005), veštačka (prinudna) ventilacija se ostvaruje ventilatorima ugrađenim na prednji zid kabine ili plafonskim ventilatorima i sistemom razvoda svežeg vazduha na više mesta u kabinu sa podesivim usmerivačima.

Radi normalizacije tople mikroklime u traktorskoj kabini, pogotovo kod traktora veće snage, koriste se i kompresorski klima uređaji.

Uz prethodno, kao sredstva zaštite vozača poljoprivredne mehanizacije od zračenja sunca, pored podesivih suncobrana, jesu i tonirana, zatamnjena, stakala kabine.

I pored svih navedenih sredstava parametri mikroklime koji vladaju u kabini menjaju se tokom vremena u zavisnosti od meteoroloških parametara (temperature i vlažnosti vazduha, vetra, intenziteta sunčevog zračenja itd) koji vladaju u datom momentu i intenziteta korišćenja mehanizacije (npr temperature motora, transmisije itd) i mogu veoma negativno da utiču na zdravlje i radnu sposobnost vozača.

Optimalna temperatura ljudskog tela kreće se od $36.1{ }^{\circ} \mathrm{C}$ do $37,0^{\circ} \mathrm{C}$. Kada se temperatura tela podigne iznad ovog nivoa, telo reaguje tako što vrši cirkulaciju krvi prema koži. Temperatura tela reguliše se kardiovaskularnim sistemom na taj način što srce potiskuje krv kroz krvne sudove prema koži, čime se povećava površina odavanja toplote, koja se dodatno pospešuje znojenjem i evaporativnim načinom odvođenja temperatura iz tela.

U slučaju da telo čoveka, iz bilo kog razloga, stvara ili prima više toplotne energije nego što može da oda, doći će do porasta temperature tela i čovek doživljava toplotni stres.

Faktori koji utiču na razmenu toplote između čovekovog tela i okruženja (u šta spada i kabina poljoprivrednih traktora), a tim i na toplotni osećaj, jesu, sa jedne strane temperatura vazduha u neposrednom okruženju čoveka, srednja temperatura zračenja prostora u kome boravi čovek, na šta zajednički deluju direktno sunčevo zračenje, zračenje okolnih struktura kabine (zagrejanih suncem) i zračenje poreklom od motora i transmisije mašine. Osim nabrojanog, brzina strujanja i vlažnost vazduha u neposrednom okruženju čoveka takođe doprinose osećaju toplotnog konfora. Na količinu stvorene toplote i njeno odavanje, a time i na osećaj toplotnog konfora čoveka, znatno utiču i fizička aktivnost koja se sprovodi, starost čoveka, metabolička aktivnost i vrsta odeće koju nosi (u smislu njene izolacione sposobnosti - Clo vrednost) (ISO 7243:2003; ISO 9920:2005; ISO 12894:2001).

U slučaju da, iz bilo kog razloga, dodje do nagomilavanja toplote u ljudskom telu mogu nastati razni oblici i stepeni oštećenja zdravlja, sa odgovarajućim simptomima i posledicama po zdravlje i radnu sposobnost izloženih osoba, a to, ponekad, može dovesti i do nastanka materijalne štete.

Kao najblaži oblik oštećenja zdravlja akumulacijom toplote u telu može se smatrati dehidracija organizma, odnosno, prevelik gubitak tečnosti iz organizma, što obično prethodi svim dalje posledicama nagomilavanja toplote u organizmu. Može da se pojavi i toplotni osip, odnosno nadražaj kože uzrokovan prekomernim znojenjem prilikom toplog, vlažnog okruženja. Javlja se u predelu vrata, gornjem delu grudnog koša, prepona, ispod grudi ili na laktovima. Toplotni grčevi se, obično, javljaju kao posledica intenzivnog $i$ teškog fizičkog rada neaklimatizovanih osoba u ambijentu s visokom temperaturom, mada se mogu pojaviti i kod osoba koji obavljaju lak ili srednje težak rad, ali su duže vremena izloženi visokim temperaturama vazduha i toplotnom zračenju. Nastup grčeva je nagao i zahvaćeni su obično listovi nogu, mišići ruku i trbušni mišići. Mogu da se jave i nesvestice i toplotna iscrpljenost koje su posledica izlaganja visokoj temperaturi i neprilagođavanja organizma na širenje krvnih sudova u koži. Ovo širenje krvnih sudova u koži jedna je od 
prvih reakcija tela na povišenu temperaturu okoline što može dovesti do kolapsa. Kao najteža posledica nakupljanja toplote u organizmu smatra se toplotni udar, stanje koje može biti opasno po život, a javlja se kod naglog, prekomernog povišenja telesne temperature i nemogućnosti organizma da temperaturu održi u normalnim granicama. Obično se javlja u situacijama kada je temperatura vazduha visoka, a vazduh zasićen vodenom parom. Toplotni udar može početi naglo, bez najave. Sunčanica se smatra oblikom toplotnog udara koji nastaje izlaganjem glave direktnom uticaju sunčevih zraka.

Indeks vlažnog globus termometra (WBGT index) je najčešće korišćeni indeks za procenu toplotnog stresa u različitim oblastima ljudske delatnosti (industriji, poljoprivredi, vojsci, sportu) (BS EN 27243; ISO 7243:2003).

WBGT indeks je empirijski indeks koji uzima u obzir toplotno zračenje, temperaturu vazduha, vlažnost vazduha i brzinu strujanja vazduha.

Može se koristiti u zatvorenim prostorima gde ne postoji uticaj sunčevog zračenja, u zatvorenim prostorima gde postoji uticaj sunčevog zračenja, ali i na otvorenom prostoru, takođe, uz korekciju za sunčevo zračenje.

U prostorijama gde ne postoji sunčevo zračenje koristi se formula za izračunavanje WBGT indeksa koja glasi: $\mathrm{WBGT}=0,7 \mathrm{tv}+0,3 \mathrm{tg}$

dok na otvorenom prostoru, gde postoji sunčevo zračenje, koristi se formula koja glasi: $\mathrm{WBGT}=0,7 \mathrm{tv}+0,2 \mathrm{tg}+0,1 \mathrm{ts}$,

pri čemu je tv - temperatura vlažnog globus termometra sa prirodnom ventilacijom; $\operatorname{tg}$ - temperatura globus termometra i ts - temperatura vazduha.

Navedene formule se mogu upotrebljavati samo u uslovima kada su prostorije dovoljno tople da kod ljudi izazivaju znojenje, dok se u hladnim prostorima koriste drugi koeficijenti.

Velika povoljnost ove metode određivanja toplotnog stresa je postojanje namenski pravljenih instrumenta, raznih proizvođača (Brüel-Kjǽr; Casella; Extech; itd) koji, nakon zadavanja osnovnih parametara (da li se merenje vrši sa ili bez korekcija za direktno sunčevo zračenje) automatski vrši izračunavanje WBGT indeksa i prikazuju ga na displeju.

\section{CILJ RADA}

Cilj ovog rada bio je da se ispita nivo toplotnog stresa kod vozača poljoprivrednih traktora i mobilnih sistema uključenih u proces spremanja silaže, $u$ vreme kada je to predviđeno godišnjim (tehnološkim) planom rada PTK „Panonija“ u Panoniji kod Bačka Topole.

\section{USLOVI I METODA MERENJA}

Merenje toplotnog stresa (WBGT indeksa) vozača poljoprivrednih traktora i mobilnih sistema obavljeno je prilikom uobičajenog režima rada prisutnih mašina u skladu sa tehnološkim postupkom spremanja silaže od zrna kukuruza, dana 08 oktobra 2014. godine, u periodu od $9^{00} \mathrm{~h}$ do $14^{00} \mathrm{~h}$, na farmi svinja PTK „Panonija“ u Panoniji kod Bačke Topole.

Vremenski uslovi spolja su bili: sunčano, potpuno bez oblaka; temperatura spoljnog vazduha $21,2^{\circ} \mathrm{C}$; temperatura globus termometra $41,9^{\circ} \mathrm{C}$; temperatura vlažnog 
globus termometra $14,5{ }^{\circ} \mathrm{C}$ (relativna vlažnost vazduha $48 \%$ ); brzina vetra $0,9-2,3 \mathrm{~m} / \mathrm{s}$; WBGT $20,6^{\circ} \mathrm{C}$.

Prevoz zrna kukuruza od parcele do farme obavljen je sa traktorom John Deere 6820 koji je radio u agregatu sa dve dvoosovinske prikolice nosivosti 8 tona. Kukuruz je istovaran na za to pripremljeno mesto na farmi. Odatle je pomoću utovarivača ULT 100 ubacivan u mlin-čekićar, nakon čega je dobijena prekrupa direktno ubacivana u prikolice nosivosti 5 tona, koje su pomoću traktora Belarus 820 i traktora John Deere 8320 odvlačene do mesta pripreme silaže odnosno objekta za siliranje (horizontalni betonski silos). „Gaženje“ odnosno priprema silaže u silosu obavljana je traktorom John Deere 8320 i guseničarom „BNT 14 oktobar“. Tokom merenja vozači traktora nosili su standardno letnje dvodelno zaštitno odelo od tankog kepera i zaštitne cipele (Clo indeks 0,75 prema ISO 9920:2005).

Takođe, tokom merenja WBGT indeksa, prozori i vrata na kabini bili su zatvoreni, sa isključenim klima uređajima (čak i ukoliko su bili ugrađeni). Bila je dozvoljena upotreba fabrički ugrađenih ventilacionih uređaja za prinudno ventiliranje kabina prema nahođenju vozača.

Za merenja WBGT indeksa za potrebe ovog rada korišćen je Heat stress monitor Brüel-Kjǽr type 1219, sa odgovarajućim kompletom davača MM 0030 i uključenom korekcijom za „direktno sunčevo zračenje“. Komplet davača MM 0030 sastoji se od globus termometra koji služi za merenje srednje temperature zračenja okoline (tg); termometra sa zaštitom od toplotnog zračenja koji služi za merenje temperature vazduha (ts) i ,vlažnog“ termometra koji služi za merenje temperatura vlažnog globus termometra sa prirodnom ventilacijom (tv), samim tim i vlažnosti vazduha (Slika 1).
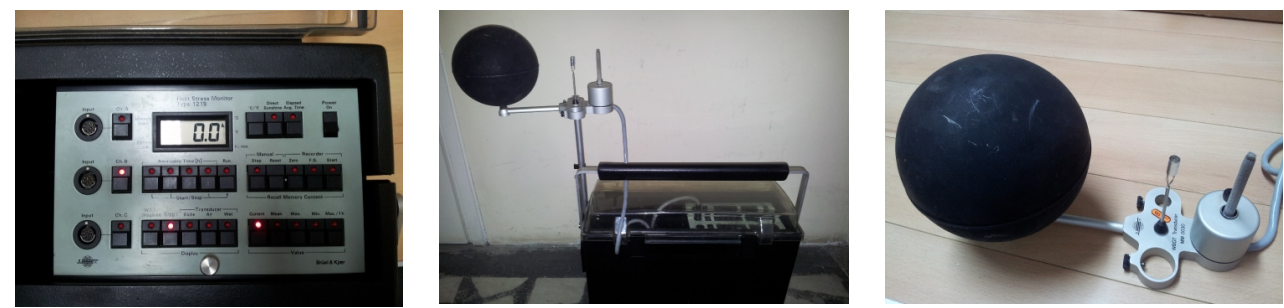

Slika 1. Heat stress monitor Brüel-Kjǽr type 1219, sa odgovarajućim davačem MM 0030 Picture 1. Heat stress monitor Brüel-Kjǽr type 1219, with transducer set MM 0030

Aparat je, prilikom merenja, smeštan u kabinu na taj način da je davač (MM0030) bio u visini grudnog koša vozača.

Merenje u svakoj kabini je trajalo 20-25 minuta, a što je prema preporukama proizvođača korišćenog instrumenta i OSHA (Technical Manual (OTM), Section III: Chapter 4.)

Određivanje granične (referentne) vrednosti WBGT indeksa (u skladu sa ISO 7243:2003) vršeno je na sledeći način:

-Vozači su bili radno angažovani na rukovanju posmatranim traktorima i mobilnim sistemima najmanje 10 radnih dana pre merenja, što se može smatrati da su bili aklimatizovani na mikroklimatske i druge uslove rada u kabinama svojih vozila. 
-Nosili su standardno letnje dvodelno zaštitno odelo od tankog kepera i zaštitne cipele (ukupan Clo indeks 0,75 prema ISO 9920:2005), za koje prema ACGIH nije potrebno vršiti odgovarajuće korekcije WBGT indeksa (Hanson MA, 1999)

-Prema preporukama ISO 7243:2003 vožnja poljoprivredne mehanizacije na „umereno neravnom terenu“ smatra se umerenim fizičkim naporom, odnosno, „Metabolic rate class 2 ".

U skladu sa napred navedenim, a prema ISO 7243:2003, referentna vrednost WBGT indeksa postavljena je na $28^{\circ} \mathrm{C}$.

\section{REZULTATI I DISKUSIJA}

Uz navedene uslove rada u kabinama posmatranih traktora i mobilnih sistema utvrđeni su parametri mikroklime i WBGT indeksi prikazani u tabeli 1.

Tabela 1. Rezultati merenja parametara mikroklime i WBGT indeksa u posmatranim traktorima i mobilnim sistemima.

Table 1. Results of microclimate and WBGT index measured in observed agricultural machinery.

\begin{tabular}{|c|c|c|c|c|c|c|}
\hline $\begin{array}{l}\text { R. } \\
\text { br. }\end{array}$ & $\begin{array}{l}\text { Traktori i mobilni sistemi/ } \\
\text { aktivnost }\end{array}$ & $\begin{array}{c}\mathrm{R} \\
\mathrm{WBGT} \\
\left({ }^{\circ} \mathrm{C}\right)\end{array}$ & $\begin{array}{c}\mathrm{I} \\
\mathrm{WBGT} \\
\left({ }^{\circ} \mathrm{C}\right)\end{array}$ & $\begin{array}{l}\mathrm{Tg} \\
\left({ }^{\circ} \mathrm{C}\right)\end{array}$ & $\begin{array}{l}\text { ts } \\
\left({ }^{\circ} \mathrm{C}\right)\end{array}$ & $\begin{array}{l}\text { tv } \\
\left({ }^{\circ} \mathrm{C}\right) \\
\mathrm{Rv} \\
(\%)\end{array}$ \\
\hline 1. & $\begin{array}{l}\text { Utovarivač ULT } 100 \\
\text { Na utovaru kukuruza }\end{array}$ & 28,0 & 23,9 & 29,6 & 22,1 & $\begin{array}{c}16,5 \\
56\end{array}$ \\
\hline 2. & $\begin{array}{l}\text { Traktor John Deere } 8320 \\
\text { Pri gaženju silaže }\end{array}$ & 28,0 & 26,5 & 37,7 & 25,3 & $\begin{array}{c}22,5 \\
77\end{array}$ \\
\hline 3. & $\begin{array}{l}\text { Guseničar BNT } 14 \text { oktobar } \\
\text { Pri gaženju silaže }\end{array}$ & 28,0 & 24,9 & 34,8 & 30,3 & $\begin{array}{c}20,9 \\
41\end{array}$ \\
\hline 4. & $\begin{array}{l}\text { Traktor Belarus } 820 \text { sa dve prikolice nosivosti } 5 \mathrm{t} \\
\text { Prilikom transporta prekrupe }\end{array}$ & 28,0 & 27,8 & 38,8 & 33,4 & $\begin{array}{c}23,6 \\
44 \\
\end{array}$ \\
\hline 5. & $\begin{array}{l}\text { Traktor John Deere } 6820 \text {, sa dve prikolice nosivosti } 8 \mathrm{t} . \\
\text { Pri transportu zrna kukuruza }\end{array}$ & 28,0 & 28,6 & 38,4 & 27,3 & $\begin{array}{l}22,2 \\
65\end{array}$ \\
\hline 6. & $\begin{array}{l}\text { Traktor John Deere } 6820 \text { sa dve prikolice nosivosti } 8 \text { t. Posle } \\
\text { transporta kukuruza, u leru }\end{array}$ & 28,0 & 22,7 & 31,3 & 24,4 & $\begin{array}{c}19,5 \\
63\end{array}$ \\
\hline \multicolumn{7}{|c|}{$\begin{array}{l}\text { Legenda / Legend: } \\
\text {-R WBGT: Referentna vrednost WBGT Indeksa / WBGT index reference value. } \\
\text {-I WBGT: Izmerena vrednost WBGT Indeksa / WBGT index measured value. } \\
\text {-tg: temperatura globus termometra / globe thermometer temperature. } \\
\text {-ts: temperatura vazduha / air temperature. } \\
\text {-tv: temperatura vlažnog globus termometra sa prirodnom ventilacijom / wet bulb temperature with natural } \\
\text { ventilation. }\end{array}$} \\
\hline
\end{tabular}

Iz predočenih rezultata merenja vidi se da su se, i pored povoljnih meteoroloških uslova (temperatura spoljnog vazduha $21,2^{\circ} \mathrm{C}$; relativna vlažnost vazduha $48 \%$; brzina vetra $0,9-2,3 \mathrm{~m} / \mathrm{s}$; WBGT $20,6^{\circ} \mathrm{C}$ ), ali velike sunčeve radijacije (temperatura globus termometra $41,9^{\circ} \mathrm{C}$ ) izmerene vrednosti WBGT indeksa u kabinama posmatranih poljoprivrednih traktora i mobilnih sistema kretali u rasponu od $22,7^{\circ} \mathrm{C}$ do $28,6{ }^{\circ} \mathrm{C}$.

Samo u jednom slučaju (u kabini traktora John Deere 6820 u agregatu sa dve prikolice nosivosti $8 \mathrm{t}$, pri transportu kukuruza) utvrđeno je da je WBGT index prešao referentnu vrednost od $28,0{ }^{\circ} \mathrm{C}$, mada je i u kabini traktora Belarus 820 sa dve prikolice 
nosivosti 5t, prilikom transporta prekrupe utvrđen WBGT index od $27,8{ }^{\circ} \mathrm{C}$, za koje se može smatrati da je na samoj granici referentne vrednosti.

Razmatrajući uticaj pojedinih praćenih parametara mikroklime na visinu izmerenog WBGT indeksa, samim tim i na intenzitet toplotnog stresa kod vozača, vidi se da je največi uticaj imalo izraženo toplotno zračenje poreklom od sunca (izmerena temperatura globus termometra $41,9^{\circ} \mathrm{C}$ ) koje je, osim direktnog delovanja na telo vozača, dovelo i do zagrevanja metalnih delove kabine, ali i ostalih delove same mašine, koji su, opet, izračivanjem dodatne toplote, značajno doprineli povećanju toplotnog stresa kod vozača.

Daljem zagrevanju kabine doprinelo je i toplotno zračenje poreklom od motora i transmisije, što se najbolje vidi kod traktora (John Deere 6820 i Belarus 820) čiji su motori transmisije bili opterećeni prilikom vuče natovarenih prikolica, ali i kod guseničara „BNT 14 oktobar" koji se malom brzinom (slabo hlađenje motora) i pod srazmerno povećanim brojem okretaja motora kretao napred-nazad „gazeći“ silažu. U slučaju traktora John Deere 6820 potvrda za ovu tvrdnju dobijena je merenjem WBGT indeksa u istom traktoru, ali nakon 15 minuta rada u „leru“ i odgovarajućem hlađenju motora i transmisije, kada je utvrđeno da je temperatura globus termometra (koja meri toplotno zračenje) opala za $7,1^{\circ} \mathrm{C}$, a WBGT index za $5,9{ }^{\circ} \mathrm{C}$.

$\mathrm{Na}$ visinu toplotnog stresa kod vozača značajno je uticala i povećana vlažnost vazduha u kabinama ispitivanih traktora i mobilnih sistema, naročito traktora John Deere 6820 gde je relativna vlažnost bila čak $15 \%$ viša u odnosu na spoljne uslove.

Uz prethodnu činjenicu, potrebno je izneti i zapažanje da je relativna vlažnost vazduha u kabinama oba traktora John Deere bili znatno povišena u odnosu na spoljnu relativnu vlažnost vazduha. Ovako povišena relativna vlažnost vazduha smanjuje mogućnost termoregulacije organizma vozača evaporacijom (isparavanjem znoja sa tela), koja termoregulacija se smatra najefikasnijim mehanizmom odavanja toplote tela, a što je rezultiralo i povišenim vrednostima WBGT indeksa, odnosno povećanim toplotnim stresom kod vozača ovih traktora. Paradoksalno, ali razlog ovome može se tražiti u dobrom zaptivanju kabine koji nije dozvolio „,izlazak“ vodene pare stvorene znojenjem i izdahnutim vazduhom vozača iz kabine, i u kvalitetnom sistemu prinudne ventilacije, koji je ubacivanjem spoljnog, hladnijeg, vazduha, i snižavanjem „tačke rose“ kabinskog vazduha, doveo do povećanog zasićenja tog vazduha vodenom parom.

Značaj dobijenih i prikazanih vrednosti toplotnog stresa koji su utvrđeni pri srazmerno povoljnim meteorološkim uslovima, je velik, naročito ukoliko se oni posmatraju u odnosu na moguće veoma visoke temperature vazduha i tla, visoke vrednosti sunčevog toplotnog zračenja, kao i u odnosu na ostale meteorološke prilike koje vladaju u kasno proleće i letnjem periodu kada je i korišćenje poljoprivredne mehanizacije najintenzivnije i mašine trpe velika naprezanja, a što ima ključni uticaj na visinu toplotnog stresa kod vozača poljoprivrednih traktora i mobilnih sistema.

U skladu sa iznetim rezultatima merenja WBGT indeksa u kabinama poljoprivrednih traktora i mobilnih sistema, odnosno, visinom toplotnog stresa kod vozača, čak i u povoljnim meteorološkim uslovima kakvi su vladali prilikom predmetnog ispitivanja, pri navedenim uslovima eksploatacije mašina, potrebno je primeniti mere prevencije i zaštite od povećanog toplotnog stresa i njegovih posledica.

Tako se preporučuje vršenje aklimatizacije vozača poljoprivrednih mašina na uslove rada pri visokim temperaturama (npr nakon povratka sa godišnjeg odmora). 
Potrebno je informisati i edukovati vozače o prevenciji mogućih posledica rada pri visokim temperaturama; praviti česte pauze radnika u hladovini; ako je moguće vršiti preraspodelu poslova (prebaciti u hladnije delove dana); unositi dovoljno tečnosti (npr na svakih 15-20 min po jedna čaša rashlađene vode); ne konzumirati alkohol, kafu i gazirane napitke; nositi laganu, svetlu i komfornu odeću od prirodnih materijala; pravilna ishrana (izbegavati tešku, vruću i obimnu hranu, jesti sveže voće i povrće); omogućiti (kupiti mašine sa njima; popraviti) korišćenje rashladnih sistema (klima uređaji, ventilatori...) uz odgovarajuću razliku spoljne i unutrašnje temperature (razlika ne veća od $8^{\circ} \mathrm{C}$ ).

\section{ZAKLJUČAK}

Dobijeni rezultati ispitivanja toplotnog stresa kod vozača poljoprivrednih traktora i mobilnih sistema, praćenih preko WBGT indeksa, ukazali su da do povećanog toplotnog stresa kod vozača, i svih posledica po radnu sposobnost, zdravlje, pa i imovinu, može da dođe i pri povoljnim meteorološkim uslovima (sunčano, potpuno bez oblaka; temperatura spoljnog vazduha $21,2^{\circ} \mathrm{C}$; temperatura globus termometra $41,9^{\circ} \mathrm{C}$; temperatura vlažnog globus termometra $14,5^{\circ} \mathrm{C}$ (relativna vlažnost vazduha $48 \%$ ); brzina vetra $0,9-2,3 \mathrm{~m} / \mathrm{s}$; WBGT $20,6^{\circ} \mathrm{C}$.) kakvi su vladali tokom ispitivanja prikazanog u ovom radu.

Značaj dobijenih vrednosti toplotnog stresa i ovih zaključaka je velik, naročito ukoliko se oni posmatraju u odnosu na visoke temperature vazduha i ostale nepovoljne meteorološke prilike koje vladaju u kasno proleće i letnjem periodu kada je korišćenje poljoprivredne mehanizacije najintenzivnije.

Sve propisane mere prevencije, bezbednosti i zdravlja na radu kod vozača poljoprivredne mehanizacije potrebno je sprovoditi tokom celokupnog procesa rada, bez obzira na vremenske prilike i režim rada poljoprivrednih mašina.

\section{LITERATURA}

[1] Prostran M (2013): Stanje i potencijali u proizvodnji hrane u Republici Srbiji, Traktori i pogonske mašine, 18(1):6-11.

[2] Nikolć R. i saradnici (2013): Motori i traktori - stanje i potrebe, Traktori i pogonske mašine, 18(1):20-27.

[3] Lazić V, Martinov M, Tešić M, Turan J. (2002): Poljoprivredna mehanizacija u agrarnom programu Vojvodine. Savremena poljoprivredna tehnika 28(1-2): 1-3.

[4] Malinović N, Mehandžić R. (2001): Stanje i potrebe mehanizacije u proizvodnji kukuruza. Savremena poljoprivredna tehnika 27 (1-2): 33-42.

[5] Martinov M, Djukić N, Tešić M. (2005): Trendovi razvoja poljoprivredne mehanizacije u svetu i primenljivost u domaćim uslovima. Savremena poljoprivredna tehnika 31 (1-2): 1-14.

[6] Časnji F, Ružić D, Stojić B. (2004): Ergonomske karakteristike savremenih traktora snage preko $120 \mathrm{~kW}$, Traktori i pogonske mašine, 9(4):48-53

[7] Časnji F, Ružić D, Muzikravić V, Poznanović N, Stojić B. (2003): Ergonomske karakteristike savremenih traktora snage $60-120 \mathrm{~kW}$, Traktori i pogonske mašine, 8(4):712.

[8] Časnji F, Ružić D. (2002): Ergonomske karakteristike savremenih traktora snage 30-60 kW. Traktori i pogonske mašine, 7(4):75-80.

[9] Ružić D, Časnji F, Muzikravić V. (2005): Značaj klimatizacije traktorske kabine. Traktori i pogonske mašine, 10(4):63-67. 
[10] ISO 7243:2003, Hot Environments-Estimation of the heat stress on working man, based on the WBGT-index (wet bulb globe temperature). Geneva: International Standards Organization.

[11] ISO 9920:2005, Ergonomics of the thermal environment-Estimation of the thermal insulation and evaporative resistance of a clothing ensemble. Geneva: International Standards Organization.

[12] ISO 12894:2001, Ergonomics of the thermal environment-Medical supervision of individuals exposed to extreme hot or cold environments. Geneva: International Standards.

[13] BS EN 27243:1994, Hot environments - Estimation of the heat stress on working man, based on the WBGT-index (wet bulb globe temperature). British Standards Institute, London.

[14] OSHA (Technical Manual (OTM), Section III: Chapter 4.) www.osha.gov/dts/osta/otm/otm_iii/otm_iii_4.html (dana 09.01.2015.)

[15] Hanson MA. (1999): Development of a Draft British Standard: the Assessment of Heat Strain for Workers Wearing Personal Protective Equipment. Ann. occup. Hyg., 43(5): 309-319.

\title{
HEAT STRESS LEVEL IN THE DRIVERS OF AGRICULTURAL TRACTORS DURING AN ENSILING
}

\author{
Prokeš B ${ }^{1}$, Mačvanin Nada $^{1}$, Simikić $\mathbf{M}^{2}$, Savin $\mathrm{L}^{2}$, Španović $\mathbf{M}^{1}$ \\ ${ }^{1}$ Institute of occupational health, Futoška 121, Novi Sad \\ ${ }^{2}$ University of Novi Sad, Faculty of Agriculture, Trg Dositeja Obradovića 8, Novi Sad, Serbia \\ e-mail: prokes@eunet.rs
}

\section{SUMMARY}

The quality of the mechanization effects the health of the driver - operator directly through the physical and chemical harmfulness present in the working environment (microclimate parameters, noise , vibration, exhaus gases, dust, etc.), causing occupational diseases, and indirectly, through multiple and diverse causes, the work related diseases.

Wet-bulbe-globe-thermometer index (WBGT index) is the most commonly used index for assessing thermal stress in different areas of human activity (industry, agriculture, military, sports) (ISO $7243: 2003$ )

Heat stress measurement (WBGT index) of drivers in observed agricultural machines was done during a normal operating modes, in accordance with the technological process of silage making.

Weather conditions were: sunny; clear sky; air temperature $21,2^{\circ} \mathrm{C}$; relative humidity $48 \%$; wind speed $0,9-2,3 \mathrm{~m} / \mathrm{s}$; WBGT index $20,6{ }^{\circ} \mathrm{C}$. set on $28^{0} \mathrm{C}$.

In accordance with the respective terms the reference value of WBGT index was

The measurement was conducted in the cabins of following tractors: John Deere 8320 and 6820; Belarus 820; wheel loader „ULT 100“ and bulldzer „BNT 14 oktobar“.

Obtained WBGT index walues were between $22,7{ }^{\circ} \mathrm{C}$ do $28,6{ }^{\circ} \mathrm{C}$. 
Considering weather conditions that ruled outside during the measurement of the WBGT index and the obtained values of the index, may be concluded that the heat stress, of drivers in the observed agricultural machinery, were, poroportionally, on a higher level, regardless of the use of the available ventilation devices in the cabins (except air conditioners where they where available).

Key words: Agricultural machinery, heat stress, WBGT index, professional risks.

Napomena: Rad predstavlja deo istraživanja na projektu „Unapređenje kvaliteta traktora i mobilnih sistema u cilju povećanja konkurentnosti, očuvanja zemljišta i životne sredine“, evidencioni broj TR 31046, koji finansira Ministarstvo prosvete i nauke Republike Srbije.

Primljeno: 07. 11. 2014. god.

Prihvaćeno: 17.11 .2014 . god. 